\title{
"Clean care for all-it's in your hands": the May 5th, 2019 World Health Organization SAVE LIVES: Clean Your Hands campaign
}

\author{
Alexandra Peters' ${ }^{1}$, Tcheun Borzykowski ${ }^{1}$, Ermira Tartari ${ }^{1}$, Claire Kilpatrick², Safiah Hwai Chuen Mai ${ }^{2}$, \\ Benedetta Allegranzi ${ }^{2}$ and Didier Pittet $^{1 *}$
}

Keywords: Infection prevention and control, Infection control, Hand hygiene, Universal health coverage, Antimicrobial resistance, World Health Organization, Healthcare-associated infection, Global health, Survey

Quality healthcare should be available to everyone. The World Health Organization's (WHO) concept of Universal Health Coverage (UHC), [1] embodies the urgent need for access to healthcare for all people around the world. In addition to access, the concept of $\mathrm{UHC}$ incorporates the critical element of the necessary quality of delivered health care services. Infection prevention and control (IPC) with hand hygiene as the most effective measure, is a practical and evidence-based approach with demonstrated impact on quality of care and patient safety across all levels of the health system.

Each year, the WHO SAVE LIVES: Clean Your Hands campaign aims to bring people together in support of hand hygiene improvement globally on or around May 5th. [2] This year's theme for global annual hand hygiene day reflects a strong focus on providing clean care equally protecting all patients and healt PLs raise to $\mathrm{PO}$ if the author response in Q2 means that the presentation of the fifth author givenName and familyName in s200 process was correct? hcare workers from infection and antimicrobial resistance transmission, across all countries, including in low-resource PLs raise to PO if the author response in Q2 means that the presentation of the fifth author givenName and familyName in s200 process was correct? settings.

\footnotetext{
* Correspondence: Didier.pittet@hcuge.ch

${ }^{1}$ Infection Control Programme and WHO Collaborating Centre on Patient

Safety, University of Geneva Hospitals and Faculty of Medicine, 4 Rue

Gabrielle-Perret-Gentil, 1211, 14 Geneva, Switzerland

Full list of author information is available at the end of the article
}

WHO urges ministries of health, health facility leaders, IPC leaders, health workers, and patient advocacy groups to contribute to effective IPC action including hand hygiene as a cornerstone of quality in healthcare (Table 1). WHO invites all healthcare facilities to join the 2019 WHO Global Survey on IPC and Hand Hygiene by using two validated assessment tools; one for evaluating the core components of IPC programmes and the other for a deep dive in hand hygiene activities (https://www.who.int/infection-prevention/campaigns/ipc-global-survey-2019/en/).

On a facility level, the use of these tools gives institutions a clear understanding of the strengths and weaknesses of their IPC and hand hygiene programmes, and provides concrete actions to address existing gaps. These tools allow institutions to improve their IPC practices and policies in a concrete and measurable way, at their own speed and in their own context. The surveys are anonymous, and global results will be made available only using aggregated data. This means that facilities and ministries of health can commit fully to working on improving IPC and patient safety without fear of scrutiny or possible negative repercussions.

Globally, this survey will allow WHO to provide a situational analysis on the level of progress of current IPC and hand hygiene activities around the world and inform future efforts and resource use for IPC capacity building and improvement. Global Surveys using the Hand Hygiene Self-Assessment Framework

(c) The Author(s). 2019 Open Access This article is distributed under the terms of the Creative Commons Attribution 4.0 International License (http://creativecommons.org/licenses/by/4.0/), which permits unrestricted use, distribution, and reproduction in any medium, provided you give appropriate credit to the original author(s) and the source, provide a link to the Creative Commons license, and indicate if changes were made. The Creative Commons Public Domain Dedication waiver (http://creativecommons.org/publicdomain/zero/1.0/) applies to the data made available in this article, unless otherwise stated. 
Table 1 May 5, 2019, World Health Organization SAVE LIVES: Clean Your Hands campaign calls to action

\begin{tabular}{ll}
\hline Campaign participants & Call to action \\
\hline Health workers & "Champion clean care - it's in your hands." \\
$I P C^{a}$ leaders & "Monitor infection prevention and control standards - take action and improve practices." \\
Health facility leaders & "Is your facility up to WHO infection control and hand hygiene standards? Take part in \\
the WHO survey 2019 and take action!" & "Does your country meet infection prevention and control standards? Monitor and act to \\
Ministries of health & achieve quality universal health coverage." \\
Patient advocacy groups & "Ask for clean care - it's your right."
\end{tabular}

aPC, infection prevention and control

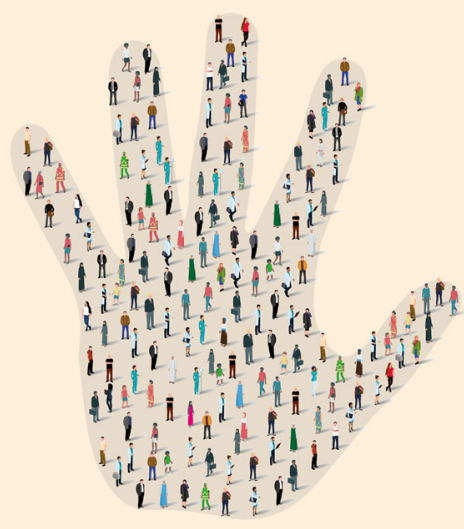

CLEAN CARE

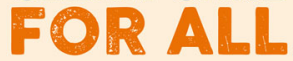

IT'S IN YOUR

ANDS

\#HandHygiene \#InfectionPrevention \#HealthForAll

Fig. 1 May 5, 2019: "Clean care for all - it's in your hands"!. The May 5, 2019, World Health Organization SAVE LIVES: Clean Your Hands campaign slogan and main promotional image (2019 hashtags: \#HandHygiene \#InfectionPrevention \#HealthForAll). Campaign participants are invited to submit photos or selfies of them holding a board with the slogan and hashtags at www.CleanHandsSaveLives.org 
were already conducted in 2011 and 2015, [3-5] making this year's survey even more crucial for tracking the implementation of hand hygiene and IPC on a global scale (Fig. 1).

Each improvement in IPC contributes toward quality UHC. "Clean care for all - it's in your hands"!

\section{Abbreviations}

IPC: infection prevention and control; UHC: universal health coverage; WHO: World Health Organization

\section{Acknowledgements}

Not applicable.

\section{Funding}

This work is supported by the World Health Organization (WHO), Geneva, Switzerland, and the Infection Control Programme and WHO Collaborating Centre on Patient Safety (SPCIMCC), University of Geneva Hospitals and Faculty of Medicine, Geneva, Switzerland; hand hygiene research activities at the SPCI/WCC are also supported by the Swiss National Science Foundation (grant no. 32003B_163262)

\section{Availability of data and materials}

Not applicable.

\section{Authors' contributions}

All authors have worked on this paper. All authors read and approved the final manuscript.

\section{Ethics approval and consent to participate}

No ethical approval required.

\section{Consent for publication}

All authors consent (see forms).

\section{Competing interests}

The authors declare that they have no competing interests.

Didier Pittet works with WHO in the context of the WHO initiative 'Private

Organizations for Patient Safety - Hand Hygiene'. The aim of this WHO

initiative is to harness industry strengths to align and improve

implementation of $\mathrm{WHO}$ recommendations for hand hygiene in health care indifferent parts of the world, including in least developed countries. In this instance, companies/industry with a focus on hand hygiene and infection control related advancement have the specific aim of improving access to affordable hand hygiene products as well as through education and research. All listed authors declare no financial support, grants, financial interests or consultancy that could lead to conflicts of interest.

\section{Publisher's Note}

Springer Nature remains neutral with regard to jurisdictional claims in published maps and institutional affiliations.

\section{Author details}

${ }^{1}$ Infection Control Programme and WHO Collaborating Centre on Patient Safety, University of Geneva Hospitals and Faculty of Medicine, 4 Rue Gabrielle-Perret-Gentil, 1211, 14 Geneva, Switzerland. ${ }^{2}$ Infection Prevention and Control Global Unit, Department of Service Delivery and Safety, World Health Organization, Geneva, Switzerland.

Received: 14 March 2019 Accepted: 29 March 2019

Published online: 17 April 2019

\section{References}

1. WHO | What is universal coverage? WHO Available at: http://www.who.int/ health_financing/universal_coverage_definition/en/. (Accessed: 19th Feb 2019).

2. WHO|SAVE LIVES: Clean Your Hands. WHO Available at: http://www.who.int/ infection-prevention/campaigns/clean-hands/en/.

(Accessed: 19th Feb 2019).
3. WHO|WHO Hand Hygiene Self-Assessment global survey for 2015. WHO Available at: http://www.who.int/gpsc/5may/hhsa framework-2015/en/. (Accessed: 19th Feb 2019).

4. Allegranzi B, Conway L, Larson E, Pittet D. Status of the implementation of the World Health Organization multimodal hand hygiene strategy in United States of America health care facilities. Am J Infect Control. 2014;42(3):224-30.

5. Kilpatrick C, Tartari E, Gayet-Ageron A, Storr J, Tomczyk S, Allegranzi B, Pittet D. Global hand hygiene improvement progress: two surveys using the WHO Hand Hygiene Self-assessment framework. J Hosp Infect. 2018;100(2):202-6.

\section{Ready to submit your research? Choose BMC and benefit from:}

- fast, convenient online submission

- thorough peer review by experienced researchers in your field

- rapid publication on acceptance

- support for research data, including large and complex data types

- gold Open Access which fosters wider collaboration and increased citations

- maximum visibility for your research: over $100 \mathrm{M}$ website views per year

At BMC, research is always in progress.

Learn more biomedcentral.com/submissions 